\title{
In vitro remineralization of enamel white spot lesions with a carrier-based amorphous calcium phosphate delivery system
}

Fang Hua ${ }^{1,2,3+}$, Jiarong Yan ${ }^{1,2+}$, Shikai Zhao ${ }^{1,4}$, Hongye Yang ${ }^{1,4}{ }^{*}$, Hong He ${ }^{1,2 *}$

${ }^{1}$ The State Key Laboratory Breeding Base of Basic Science of Stomatology (Hubei-MOST) \& Key Laboratory of Oral Biomedicine Ministry of Education, School \& Hospital of Stomatology, Wuhan University, 237 Luoyu Rd, Wuhan, 430079 China

2 Department of Orthodontics, School \& Hospital of Stomatology, Wuhan University, 237 Luoyu Rd, Wuhan, 430079 China

${ }^{3}$ Division of Dentistry, School of Medical Sciences, Faculty of Biology, Medicine and Health, Manchester Academic Health Science Centre, University of Manchester, Oxford Rd, Manchester, M13 9PL UK

${ }^{4}$ Department of Prosthodontics, School \& Hospital of Stomatology, Wuhan University, 237 Luoyu Rd, Wuhan, 430079 China

+ These authors are joint first authors and contributed equally to this work.

* Corresponding Author:

Hong He, Department of Orthodontics, Hubei-MOST KLOS \& KLOBM,

School \& Hospital of Stomatology, Wuhan University,

Luoyu Road 237, Wuhan 430079, China.

E-mail: drhehong@whu.edu.cn

Hongye Yang, Department of Prosthodontics, Hubei-MOST KLOS \& KLOBM,

School \& Hospital of Stomatology, Wuhan University,

Luoyu Road 237, Wuhan 430079, China.

E-mail: yanghongye@whu.edu.cn 


\section{How to Cite:}

Fang Hua, Jiarong Yan, Shikai Zhao, Hongye Yang, Hong He. Clinical Oral Investigations, 2019. doi: 10.1007/s00784-019-03073-x

doi: $10.1007 / \mathrm{s} 00784-019-03073-\mathrm{x}$

PMID: 31705307

Please note that this is a post-print version (after peer-review) for the purpose of self-archiving. Please download the final published version from the publisher's website:

https://link.springer.com/article/10.1007\%2Fs00784-019-03073-x 


\begin{abstract}
Objectives: To achieve in vitro remineralization of enamel white spot lesions (WSLs) via a mesoporous delivery system of amorphous calcium phosphate (ACP) precursors.
\end{abstract}

Materials and methods: Amine-functionalized expanded pore mesoporous silica (aMSN) was loaded with polyacrylic acid-stabilized amorphous calcium phosphate (PAA-ACP) to develop a carrier-based delivery system (PAA-ACP@aMSN). Thirty-six artificial WSLs samples were created and randomly assigned to three treatments: artificial saliva solution (negative control, $n=12)$, casein phosphopeptide-amorphous calcium phosphate (CPP-ACP) slurry ( = 12), and PAA-ACP@aMSN slurry ( $n=12)$. Surface microhardness, Raman intensity, and color were measured before/after artificial demineralization and after remineralization treatments to evaluate the remineralization level of each sample. SEM images were taken on the surface and cross-section of samples to observe microstructure changes.

Results: The surface microhardness recovery ratio (\%SMHRR), Raman intensity change ratio (\%lCR), and color recovery ratio (\%CRR) were not significantly different between CPP-ACP and PAA-ACP@aMSN groups ( $P$ > 0.05), but both of them had significantly higher \%SMHRR, \%ICR, and \%CRR values than negative control $(P<0.01)$. SEM images showed that apparent enamel prism imprints and inter-prism gaps in negative control were masked by mineral deposition in the PAA-ACP@aMSN and CPP-ACP groups.

Conclusions: PAA-ACP@aMSN has an ability to remineralize enamel WSLs.

Clinical relevance: The carrier-based amorphous calcium phosphate delivery system has great potential to serve as a remineralizing agent for the treatment of WSLs.

Key words: Enamel, Remineralization, White spot lesions, Amorphous calcium phosphate, Mesoporous silica 


\section{Introduction}

Improving facial esthetics is an objective of orthodontic treatment. ${ }^{1}$ However, a frequent complication of fixed orthodontic therapy is the subsurface enamel porosity due to carious demineralization (also known as white spot lesions (WSLs)), which can arise in 25 to $97 \%$ of orthodontic patients and compromise the esthetic outcome of their orthodontic treatment. ${ }^{2,3}$ After removing appliances, a natural improvement in WSLs may occur during the first 6 to 24 months; however, such natural remineralization is always limited and some WSLs can last for more than 10 years. ${ }^{4}$

As the demineralization of enamel surfaces is mainly caused by acidic attacks from oral biofilms and the resultant dissolution of hydroxyapatite into $\mathrm{Ca}^{2+}$ and $\mathrm{PO}^{3-}{ }^{5}, \mathrm{a}$ variety of remineralizing agents that can neutralize acids and/or release desirable metal cations have been used to prevent and treat WSLs. However, recent systematic reviews of clinical research have suggested that the aforementioned therapies including topical fluoride have limited preventive or therapeutic effects on WSLs. ${ }^{6,7}$ Professionally applied fluoride varnish may be effective, ${ }^{8,9}$ but this approach is onerous and may be costly. ${ }^{10}$ Furthermore, the use of high-concentration topical fluoride may result in unsightly enamel surfaces stained with organic debris. ${ }^{11}$ Therefore, WSLs still remain a clinical problem and require further research.

Recently, a novel theory about biomineralization has been proposed, ${ }^{12}$ which believes that a solution-based biomimetic mineralization system has outstanding effects in the remineralization of a mineral substance. ${ }^{13}$ Based on this theory, amorphous calcium phosphate (ACP) has been confirmed as an effective precursor of dentin and bone biomineralization. ${ }^{14}$ Previous studies have shown that ACP could be stabilized in a moldable and nanoparticulate status called the polymer-induced liquid precursor (PILP) phase by using biomimetic analogs as ACP precursor stabilizers, ${ }^{15}$ and then transformed into apatite crystallites. ${ }^{16}$ Polyacrylic acid-stabilized amorphous calcium phosphate (PAA-ACP) has been proved capable of remineralization. ${ }^{17}$ Tay et al. 
further developed a carrier-based delivery system, amine-functionalized mesoporous silica (aMSN) loaded with PAA-ACP, achieved periodic replenishment of the mineralizing precursors, and realized intrafibrillar mineralization of collagen. ${ }^{18}$ Due to the fact that this carrier-based precursor delivery system (PAAACP@ aMSN) is more practical for in vivo remineralization of human hard tissues, it has great potential to serve as a remineralizing agent for the treatment of WSLs. However, to our knowledge, no related reports were available until now.

Therefore, the objectives of this study were to evaluate the remineralization capability of PAA-ACP@aMSN for artificial WSLs, in comparison with a commercially available remineralization agent (casein phosphopeptide amorphous calcium phosphate, CPPACP). Towards this end, ultrastructural characterization and elemental mapping of PAA-ACP@aMSN were conducted with a transmission electron microscopy (TEM). Furthermore, the Vickers hardness testing for surface microhardness changes, Raman intensity mapping for surface mineral content changes, color components $\left(L^{*}, a^{*}, b^{*}\right)$ measurement for surface color changes, and scanning electron microscope (SEM) image analysis for surface and cross-sectional microstructure changes were performed. Our null hypothesis was that PAA-ACP@aMSN had no remineralization effect for enamel WSLs.

\section{Methods and Materials}

\section{Sample preparation}

Forty human upper premolars extracted for orthodontic treatment purposes were obtained after (1) getting the donors' informed consent under a protocol approved by the Ethics Committee for Human Studies of the School \& Hospital of Stomatology, Wuhan University (No. 2017-49) and (2) excluding teeth with caries, restorations, WSLs, and fracture. After removing all gingiva, odontolith, and other attachments on surfaces, the teeth were rinsed under running deionized water for 5 min and then refrigerated in $0.1 \%$ thymol at $4{ }^{\circ} \mathrm{C}$ before experiment. ${ }^{19}$ Roots were excised and crowns were separated longitudinally into buccal parts and lingual parts. All crowns 
were embedded in an epoxy resin with the buccal or lingual surface facing upwards. Enamel surfaces were then ground and polished flat with 800-, 1000-, 1200-, $1500-$, 2000-, 2500-, and 3000-grit SiC emery paper (Yuli Abrasive Belts, Shanghai, China) under running deionized water, and polished with $500 \mathrm{~nm}$ Al O powders to obtain glossy surfaces of enamels. Subsequently, these samples were pressure flushed by water spray for $15 \mathrm{~s}$ followed by ultrasonic cleaning in deionized water 3 times ( 5 min per time) to remove any residue. After drying, the enamel surfaces were covered by two layers of anti-water nail varnish leaving a $1 \mathrm{~mm} \times 3 \mathrm{~mm}$ experiment window. ${ }^{20}$

Enamel surface microhardness $(\mathrm{SMH})$ was measured for all samples using a Vickers microhardness tester (methods described later). Samples with a Vickers microhardness number $(\mathrm{VHN})>430$ or $<340$ were excluded. A total of 36 samples were finally retained for further experiment.

Artificial enamel demineralization was created by immersing samples in a demineralizing solution $\left(10 \mathrm{mM} \mathrm{NaH} \mathrm{PO}_{4}-2 \mathrm{H}_{2} \mathrm{O}, 2.2 \mathrm{mM} \mathrm{CaCl}{ }_{2}-2 \mathrm{H}_{2} \mathrm{O}, 50 \mathrm{mM}\right.$ acetic acid, $\left.100 \mathrm{mM} \mathrm{NaCl}, 1 \mathrm{ppm} \mathrm{NaF}, 5 \mathrm{mM} \mathrm{NaN}_{3}\right)$, ${ }^{21}$ with the $\mathrm{pH}$ adjusted to 4.5 using $1 \mathrm{M}$ $\mathrm{NaOH}$ solution. The demineralization process was implemented at $37^{\circ} \mathrm{C}$ and lasted for 4 days. Thereafter, samples were pressure flushed by water spray for $15 \mathrm{~s}$ followed by ultrasonic cleaning in deionized water for 3 times ( 5 min per time) to terminate demineralization.

\section{Preparation of PAA-ACP@aMSN}

The methods for carrier-based precursor delivery were developed according to Tay and colleagues' studies ${ }^{18,22}$. Seven milliliters mesitylene (TMB) and $1 \mathrm{~g}$ cetyltrimethylammonium bromide (CTAB) were dissolved in a solution that contained $480 \mathrm{~mL}$ water and $3.5 \mathrm{~mL} 2 \mathrm{M} \mathrm{NaOH}$. This compound was mixed round intensely for $4 \mathrm{~h}$ at $80{ }^{\circ} \mathrm{C}$. Then, $5 \mathrm{~mL}$ of tetraethyl orthosilicate (TEOS) was added quickly to the mixture and then stirred for $2 \mathrm{~h}$. The sediment was centrifuged and then rinsed with deionized water and ethanol three times and dried overnight at $60^{\circ} \mathrm{C}$. The dry powers 
were then calcined at $550{ }^{\circ} \mathrm{C}$ in air for $5 \mathrm{~h}$ to remove pore swelling agent (TMB) and structural template (CTAB). For the preparation of amine-functionalized MSN (aMSN), $500 \mathrm{mg} \mathrm{MSN}$ was suspended in $100 \mathrm{~mL}$ anhydrous toluene with $2 \mathrm{~mL} 3$-aminopropyl triethoxysilane (APTES) added afterwards into the mixture. The mixture was then refluxed for $24 \mathrm{~h}$, filtered, rinsed with ethanol for 3 times, and dried for $12 \mathrm{~h}$ at $80{ }^{\circ} \mathrm{C}{ }^{18}$

Polyacrylic acid (PAA) was added to $9.0 \mathrm{mM} \mathrm{CaCl} 2-2 \mathrm{H}_{2} \mathrm{O}$ solution to obtain a PAA concentration of $1000 \mu \mathrm{g} / \mathrm{mL}$. PAA-ACP was synthesized by rapid mixing of uniform volumes of $4.2 \mathrm{mM} \mathrm{Na} \mathrm{HPO}$ and PAA-contained $\mathrm{CaCl}_{2}-2 \mathrm{H}_{2} \mathrm{O}$ solution at room temperature. Then, $200 \mathrm{mg}$ aMSN was added into $50 \mathrm{~mL}$ of PAA-ACP solution and stirred for $24 \mathrm{~h}$ at room temperature. PAA-ACP@aMSN paste was obtained by centrifuging the above mixture. After washing with deionized water, the cataplasm was stored at $-20{ }^{\circ} \mathrm{C}$ before use.

The ultrastructural features of aMSN and PAA-ACP@aMSN were obtained using transmission electron microscopy (TEM; JEM-1230; JEOL, Tokyo, Japan) at $110 \mathrm{kV}$. Scanning TEM-energy dispersive X-ray (STEM-EDX) elemental mapping was performed with a Tecnai G2 scanning TEM (FEI, Hillsboro, OR, USA) at $200 \mathrm{kV}$ to acquire elemental mapping of PAA-ACP@aMSN. Thermogravimetric analysis (Netzsch STA 2500 Regulus, German) with a warming rate of 10 degrees per minute from indoor temperature to $1550{ }^{\circ} \mathrm{C}$ was used to measure the loading efficiency of aMSN.

\section{Group assignment}

All 36 samples were randomly assigned to three groups (12 samples per group): (1) artificial saliva solution (negative control, NC), (2) CPP-ACP (5-10\%wt CPP-ACP, GC Corp, Tokyo, Japan; Supplementary Table 1), and (3) PAAACP@ aMSN according to a random number sequence generated by computer.

\section{Surface microhardness measurement}


All samples' surface microhardness $(\mathrm{SMH})$ was measured using a Vickers microhardness tester (Taiming Corporation, Shanghai, China) with a Vickers diamond. $^{23}$ The loading force was $50 \mathrm{~g}$ and loading time was $10 \mathrm{~s}$, and the $\mathrm{SMH}$ number was automatically measured by the tester. Five indentations, at least $100 \mu \mathrm{m}$ apart from each other, were taken on the center of each sample with an average value calculated as the sample's Vickers microhardness number (VHN). The VHN of each sample was measured before and after artificial demineralization:

- SMHO: Surface microhardness of enamel sample before artificial demineralization

- SMH1: Surface microhardness of enamel sample after artificial demineralization

\section{Surface Raman intensity mapping}

The surface mineral content of enamel was measured using a micro-Raman spectrometer (i-Raman Portable Raman Spectrometer, B\&W TEK Inc., USA), with a 785-nm laser source and 300-mW potency to gain spectra. Raman intensity mapping was collected under the following conditions: 7000 ms integration time and 0-3200 $\mathrm{cm}^{-1}$ Raman shift range at room temperature. Each sample's Raman intensity mapping was obtained five times by shining the focused laser spot on five different points of enamel surface using a fiber optic- based system (105 LM, NA 0.22, B\&W TEK Inc., USA). ${ }^{24}$ Four characteristic peaks of phosphate occurred at about 1045, 960, 430, and $580 \mathrm{~cm}^{-1}$ on the Raman intensity mapping. The peak at $960 \mathrm{~cm}^{-1}$ was measured to represent enamel mineral content because it is the strongest among the above four peaks in enamel and can be used as the enamel mineral content indicator. 20, 24,25

After gaining spectral data, the BWSpec 4 spectroscopic software was used to visualize Raman intensity mappings, and the Raman relative intensity of phosphate at $960 \mathrm{~cm}^{-1}$ was measured. Each sample's Raman intensity mapping was measured before and after artificial demineralization:

- I-Baseline: Raman relative intensity at $960 \mathrm{~cm}^{-1}$ before artificial demineralization

- I-Lesion: Raman relative intensity at $960 \mathrm{~cm}^{-1}$ after artificial demineralization 


\section{Surface Raman intensity mapping}

The enamel's surface color was measured with a color measurement system, using CIE $L *, a *$, and $b *$ values for quantification. ${ }^{26}$ The $L$ value reveals lightness, a value represents the position of red or green axes, and b value demonstrates the position of yellow or blue axes. ${ }^{27}$ The color measurement system was made up of a spectrophotometer (PR-650 Spectra Scan, equipped with MS-75 and SL-0.5X lens; Photo Research, Chatsworth, GA) and two fiber optic light cables positioned at a $45^{\circ}$ angle left-and-right to the spectrophotometer. Each sample was held right in front of the spectrophotometer to make sure the observation angle was $0^{\circ}$ and the illumination angle was $45^{\circ}$. All measurements were executed under the same illumination. The $L *, a *$, and $b *$ values were measured three times for each sample before and after artificial demineralization. A white reflectance standard tile was used to calibrate the spectrophotometer before each measurement. After obtaining the L*, $a *$, and $b *$ values of each sample, the color change before and after artificial demineralization $(\triangle \mathrm{E} 0)$ were calculated using the following formula: ${ }^{28}$

- $\Delta \mathrm{E}=\left[(\Delta \mathrm{L} *)^{2}+(\Delta \mathrm{a} *)^{2}+(\Delta \mathrm{b} *)^{2}\right]^{1 / 2}$

\section{Remineralization protocol}

The remineralization procedure was implemented three times per day $(2 \mathrm{~min}$ per application) at 09:00, 15:00, and 23:00 for 7 days consecutively. In CPP-ACP and PAAACP@aMSN groups, agents were continuously brushed onto the enamel surface within the window area using a microbrush, while in the NC group, enamel surfaces were brushed with an artificial saliva solution. For the CPP-ACP and PAA-ACP@aMSN groups, a small weighing scoop was used to obtain the paste to make sure the same volume $(100 \mu \mathrm{L})$ of CPP-ACP or PAAACP@ aMSN paste was used in each application. Thereafter, the enamel surface was rinsed under running deionized water. All operations were performed by a single operator. Following every remineralization procedure, samples were incubated in an artificial saliva solution $(0.7 \mathrm{mM} \mathrm{CaCl}, 0.2$ $\mathrm{mM} \mathrm{MgCl}$, $4.0 \mathrm{mM} \mathrm{KH}_{2} \mathrm{PO}_{4}, 20 \mathrm{mM}$ HEPES, $30.0 \mathrm{mM} \mathrm{KCl}$, pH adjusted to 7.0 by $1 \mathrm{M}$ $\mathrm{NaOH})^{20}$ at $37^{\circ} \mathrm{C}$ to simulate natural remineralization in oral environment which was 
refreshed every day. After 7 days remineralization procedure, samples were thoroughly rinsed under running deionized water followed by ultrasonically cleaning in deionized water for 5 min to remove any residual agent.

\section{Characterizations of surface post-remineralization}

After remineralization, all samples' surface microhardness, Raman intensity mapping, and $L *, a *$, and $b *$ values were acquired again using the same protocols described in the previous sections. Sample's surface microhardness after the demineralization process was marked as $\mathrm{SMH}$ 2. A specific formula was used to calculate the recovery ratio of surface microhardness (\%SMHRR): \%SMHRR $=(\mathrm{SMH} 2-\mathrm{SMH} 1) /(\mathrm{SMHO}-$ $\mathrm{SMH} 1) \times 100 \% .^{29}$ Samples' Raman relative intensity of phosphate at $960 \mathrm{~cm}^{-1}$ after remineralization was marked as I-Post. The Raman intensity change ratio (\%ICR) was calculated using the following formula $a^{20,25}$ to quantify the surface mineral content change ratio after remineralization, assuming that the enamel before artificial demineralization was $100 \%$ in mineral content: $\% I C R=[(I-$ Post $/ I-$ Baseline $)-(I$ - Lesion/l - Baseline)] $\times 100 \%$. The change in the enamel surface color before and after remineralization ( $\triangle \mathrm{E} 1)$ was calculated using the same formula described in "Surface color measurement." Enamel surface color recovery ratio (\%CRR) was then calculated using the following formula: \%CRR $=(\triangle \mathrm{E} 1 / \Delta \mathrm{E} 0) \times 100 \%$. EDS (Quanta 200 FEG, FEE, Eindhoven, the Netherlands) and XRD (X'Pert PRO, PANalytical, Almelo, the Netherlands) were used to characterize the elementary composition and crystal texture of mineral deposits in each group.

\section{SEM imaging}

After remineralization, the surface and cross-section morphologies of enamel were observed using an SEM (Quanta 450 FEG, FEl, Eindhoven, Netherlands). Two samples in each group were fractured across the demineralization area in a buccolingual direction to create a cross-section view without further grinding or polishing in order to protect the microstructure. Another two samples from each group were chosen for 
surface observation. These samples were dried in a desiccator for $72 \mathrm{~h}$ and then gold coated using a vacuum evaporator (EIKOIB-3 ion coater, Hitachi, Japan). Enamel surface and cross-section micrographs were obtained in a back-scattered electron mode with $20 \mathrm{kV}$ accelerate voltage. Micrographs before and after artificial demineralization were also taken using the same method.

\section{Statistical analysis}

All microhardness, Raman, and color-related data were analyzed with the one-way ANOVA and Tukey's multiple comparison tests. Level of statistical significance was set at $\alpha=0.05$.

\section{Results}

\section{Ultrastructural features and thermogravimetric analysis of PAA-ACP@aMSN}

The TEM images for aMSN and PAA-ACP@aMSN are shown in Fig. 1. Regular hexagon microporosities were evenly distributed over the entire aMSN microparticulate (Fig. 1a). After loading PAA-ACP into aMSN, microporosities became indistinct and irregular (Fig. 1b). Figure 1c shows the ultrastructure of one single PAA-ACP@aMSN and its STEM-EDX elemental mapping. The strong intraparticulate $\mathrm{Ca}$ (green) and P (blue) signals indicate the infiltration of PAA-ACP nanoparticles into the mesopores. Thermogravimetric analysis of aMSN and PAAACP@aMSN are shown in Supplementary Fig. 1. aMSN showed a total weight loss of 14.24 wt\% while the value of PAA-ACP@aMSN was 25.04 wt $\%$. The extra weight loss was $10.80 \mathrm{wt} \%$ which may come from the decomposition of PAA in PAAACP@aMSN, indicating that the amount of PAA-ACP adsorbed on aMSN was higher than $10.80 \mathrm{wt} \%$.

\section{Surface microhardness}

Results for the recovery percentage of surface microhardness (\%SMHRR) are presented in Fig. 2 and Supplementary Table 2. No significant difference ( $P=0.613)$ was found between CPP-ACP (Mean \pm SD \%; $71.0 \pm 11.7$ ) and PAAACP@ aMSN 
(75.2 \pm 7.9 ), but both of them had a significantly higher \%SMHRR than the NC group (43.4 $\pm 12.4 ; P<0.0001$ for both groups).

\section{Surface mineral content}

Figure 3 and Supplementary Table 3 demonstrates the surface Raman intensity change ratio (\%ICR) for different groups. The CPP-ACP $(29.7 \pm 4.9)$ and PAAACP@ aMSN $(24.1 \pm 9.1)$ groups recorded a significantly higher value when compared to control (13.2 $\pm 6.7 ; \mathrm{P}<0.01$ for both groups), while no significant difference was found between CPP-ACP and PAA-ACP@aMSN (P = 0.145).

\section{Surface color}

Results for the recovery percentage of the enamel surface color recovery ratio (\%CRR) are shown in Fig. 4 and Supplementary Table 4. Both the CPP-ACP (63.0 \pm 13.1) and PAA-ACP@aMSN (61.7 \pm 20.2$)$ groups showed a significantly higher \%CRR than the NC group (36.9 $\pm 20.0, P<0.01$ for both groups). No significant difference was seen between CPP-ACP and PAA-ACP@aMSN (P = 0.984).

\section{Surface and cross-section SEM observations}

The micrographs of enamel surfaces are shown in Fig. 5 at $\times 5000$ and $\times 20,000$ magnifications. In baseline images, the enamel surface was smooth and flat, with visible scratches caused by polishing (Fig. 5a). In images taken after the demineralization process, inter-prism gaps induced by demineralization were distinct on the enamel surface (Fig. 5b). In the NC group images, enamel prism imprints remained apparent (Fig. 5c). However, in the CPP-ACP and PAAACP@ aMSN groups, the enamel surfaces were relatively smooth and prism imprints were no longer distinct, indicating substantial mineral deposition which covered previously exposed enamel prisms and filled inter-prism gaps (Fig. 5d, e). 
Figure 5 also presents the cross-section micrographs at $\times 2000$ and $\times 10,000$ magnifications. At baseline, surface of cross-section was almost smooth and the prismatic structure could not be easily recognized (Fig. 5a). After demineralization, enamel prisms and inter-prism gaps were apparent and exhibited roughness and porosities (Fig. 5b). The cross-section enamel micrographs of NC group were similar to those before remineralization (Fig. 5C). In the images of CPP-ACP and PAAACP@aMSN groups, prisms and inter-prism gaps were masked with mineral depositions and prismatic structures were no longer distinct (Fig. 5d, e).

\section{EDS and XRD analysis of mineral deposits}

EDS results of specimens before and after remineralization are shown in Fig. 6. The calcium phosphorus atomic ratio was 1.47 for normal enamel. For the NC, CPP-ACP, and PAA-ACP@aMSN groups, the ratio was 1.49, 1.49, and 1.46, respectively, which means that mineral deposits in all the three groups after remineralization had similar $\mathrm{Ca}-\mathrm{P}$ atomic ration to normal enamel.

$\mathrm{XRD}$ result is shown in Fig. 7. Because of the presence of embedding material around the enamel, all samples' XRD patterns had two impurity peaks of epoxy resin. Ignoring the impurity peaks, all three experimental groups showed the same diffraction pattern to normal enamel which indicated mineral deposits in all three groups had the same crystal texture to normal enamel. In addition, For all three groups, the diffraction peaks at $25.9^{\circ}(002), 28.1^{\circ}(210), 31.8^{\circ}(211), 34.0^{\circ}(202)$, $49.5^{\circ}(213), 53.1^{\circ}(004), 61.7^{\circ}(214)$, and $64.1^{\circ}$ (323/304) corresponded well to standard XRD pattern (JCPDS 09-0432) of HA, which indicate the mineral deposits were mostly hydroxyapatite.

\section{Discussion}

Enamel WSLs are an unmet challenge for dental profession. ${ }^{30}$ As these lesions are caused by acidic attacks from bacterial biofilms and the resultant demineralization, ${ }^{5}$ 
numerous efforts have been made to treat WSLs with remineralization, which means the regain of mineral content by precipitating calcium and phosphate from external sources into small pores on top of enamel prisms and the inter-prism gaps resulted from demineralization. ${ }^{31}$

As a commercially available agent, CPP-ACP has been proved effective for remineralizing enamel in vitro ${ }^{21,32}$ and in vivo ${ }^{33}$ Casein phosphopeptide (CPP) is a saliva biomimetic that has the ability to stabilize calcium and phosphate ions, and thereby enhance mineral solubility and bioavailability. ${ }^{34}$ Therefore, CPP-ACP nanocomplexes can maintain a state of supersaturation of ACP nanoparticles in the oral environment and facilitate remineralization through the release of them during acidic attacks or changes in ion concentration. ${ }^{31}$ According to previous studies, CPPACP can induce subsurface remineralization and significantly improve the strength, esthetics, and acid resistance of WSLs. ${ }^{35}$

Similar to CPP, PAA is a biomimetic analogue that can stabilize ACP precursors and induce them to remineralize dentin and enamel. ${ }^{17,36}$ However, in order to make PAAACP more stable and periodically replenished, a mesoporous carrier would be highly desirable. Mesoporous silica nanoparticles (MSN) are remarkable biological delivery systems for a variety of drugs due to their large pore volume, high internal surface area, and cost effectiveness. ${ }^{37}$ In addition, we used amine to functionalize MSN into aMSN to make it positively charged for efficient loading of negatively charged PAA-ACP. ${ }^{18,38}$ Proof of the efficiency of this strategy can be found in previous studies. ${ }^{18,22}$

In this study, the remineralization capability of PAA-ACP@aMSN was evaluated using artificial saliva solution as a negative control and CPP-ACP as a positive control. Similar to previous relevant studies, artificial WSLs were established by immersing human premolars into a demineralization solution. ${ }^{21}$ Also, the level of 
remineralization was quantified using three different methods, namely the Vickers microhardness test, Raman intensity mapping, and color components measurement. Surface microhardness tests have been widely used to evaluate the degree of enamel demineralization, ${ }^{20,21,25,39}$ for which an increase suggests mineral regain and improvement in enamel crystalline structure. ${ }^{40,41}$ The Raman microspectroscopy is a method for measuring mineral content of enamel; ${ }^{42}$ a phosphate intensity peak at $960 \mathrm{~cm}$ represents the hydroxyapatite mineral amount of enamel. ${ }^{43,44}$ Evaluation of the esthetic recovery of treated specimen is necessary since the chalky appearance caused by demineralization is also a characteristic of WSLs. The $L * a *$, and $b *$ values used in the present study is a quantitative index of color enacted by the Commission International de l'Eclariage (CIE) $1978 .{ }^{45}$ Additionally, SEM was performed to observe both the surface and cross-section microstructures of enamel to obtain more morphological details.

As shown in surface microhardness, Raman intensity, and color change results, both CPP-ACP and PAA-ACP@aMSN groups exhibited significantly more recovery than the negative control group, while no significant difference was found between PAAACP@aMSN and CPP-ACP (Figs. 2, 3, and 4 and Supplementary Tables 2, 3, and 4). These findings were supported by our SEM observations: enamel prism imprints and inter-prism gaps remained apparent in the negative control group, whereas in CPPACP and PAA-ACP@aMSN images, these structures were covered by mineral deposition and no longer distinct (Fig.5).

In addition, EDS and XRD analysis were used to explore the elementary composition and crystal texture of mineral deposits. The calcium-phosphorus atomic ratio of mineral deposits in all three groups were close but a little bit lower than 1.67 which is the calcium-phosphorus atomic ratio of pure hydroxyapatite $(\mathrm{Ca}(\mathrm{PO})(\mathrm{OH}))(\mathrm{Fig}$ 6). This may be because hydroxyapatite inside the enamel was not completely pure, other elements like $\mathrm{Mg}, \mathrm{K}$, or $\mathrm{Na}$ may replace $\mathrm{Ca}$ which resulted in decline of the 
calcium-phosphorus proportion. In addition, calcium-deficient hydroxyapatite is a common calcium-phosphorus crystalline form in vivo which also cause the decrease of calcium-phosphorus atomic ratio. ${ }^{46} \mathrm{XRD}$ analysis is a usual method to analyze the crystal structure of enamel and hydroxyapatite. ${ }^{47,48}$ Our XRD result showed the crystal structure characterization of normal enamel and mineral deposition of the three groups (Fig. 7). Remineralization enamel from all three experimental groups had the same diffraction pattern to normal enamel which meant they had the same crystal texture. Furthermore, the diffraction peaks at $25.9^{\circ}(002), 28.1^{\circ}(210), 31.8^{\circ}$ (211), $34.0^{\circ}(202), 49.5^{\circ}(213), 53.1^{\circ}(004), 61.7^{\circ}(214)$, and $64.1^{\circ}(323 / 304)$ corresponded well to standard XRD pattern (JCPDS 09-0432) of HA further indicated that the mineral deposits were mostly hydroxyapatite.

The release of PAA-ACP from aMSN could be attributed to the competitive displacement of physisorbed PAA-ACP by zwitterions. ${ }^{49}$ The potential remineralization mechanism may be as follows (Fig. 8): PAA-ACP nanoparticles are released from aMSN through the competitive displacement of zwitterions; subsequently, driven by the force from electrostatic interaction or capillary action. ${ }^{16,50}$ The defects and gaps on enamel caused by demineralization may become nucleation sites for calcium and phosphate ${ }^{47}$ which may help PAAACP attach and release calcium and phosphate. Therefore, PAA-ACP infiltrate into the surface of demineralized enamel, release calcium and phosphate. Subsequently, these calcium and phosphate ions transform into hydroxyapatites on the top of enamel prisms and the gaps between them. Through the formation and deposition of hydroxyapatites, demineralized enamel surface is remineralized.

Although the remineralization capability of PAA-ACP@aMSN is comparable with CPP-ACP, PAA-ACP@aMSN has several advantages. Firstly, it can act as nanofillers in adhesive resins due to the excellent mechanical properties of MSN, which give it broader prospects for application. Secondly, while loaded with PAA-ACP, aMSN can 
still adsorb other nanodrugs such as antibacterial or protein-repellent agents ${ }^{51,52}$ rendering the delivery system multifunctional.

\section{Conclusions}

The present study showed that the carrier-based precursor delivery system PAAACP@ aMSN could effectively realize the in vitro remineralization of enamel WSLS.

\section{Funding information}

This research was funded by the National Natural Science Foundation of China (No. 81701012) and China Postdoctoral Science Foundation (No. 2018 M640735).

\section{Compliance with ethical standards}

Conflict of interest The authors declare that they have no conflict of interest.

Ethical approval All procedures performed in studies involving human participants were in accordance with the ethical standards of the institutional and/or national research committee and with the 1964 Helsinki Declaration and its later amendments or comparable ethical standards. While the ethical research protocol was approved by the Ethics Committee for Human Studies of the School \& Hospital of Stomatology, Wuhan University (No. 2017-49)

Informed consent Informed consent was obtained from all individual participants included in the study.

Disclaimer The funders had no role in the design of the study; in the collection, analyses, or interpretation of data; in the writing of the manuscript, or in the decision to publish the results. 


\section{References}

1. Mitchell L (2007) An introduction to orthodontics, 3rd edn. Oxford University Press, Oxford

2. Julien KC, Buschang PH, Campbell PM (2013) Prevalence of white spot lesion formation during orthodontic treatment. Angle Orthod 83(4):641-647

3. Paula AB, Fernandes AR, Coelho AS, Marto CM, Ferreira MM, Caramelo F, do Vale F, Carrilho E (2017) Therapies for white spot lesions-a systematic review. J Evid Based Dent Pract 17(1):23-38

4. Shungin D, Olsson Al, Persson M (2010) Orthodontic treatment-related white spot lesions: a 14-year prospective quantitative follow-up, including bonding material assessment. Am J Orthod Dentofac Orthop 138(2):136.e1-8; discussion $136-7-137$

5. Ren Y, Jongsma MA, Mei L, van der Mei HC, Busscher HJ (2014) Orthodontic treatment with fixed appliances and biofilm formation-a potential public health threat? Clin Oral Investig 18(7):1711-1718

6. Hua F, Yang H, He H (2018) Current enamel remineralization therapies have limited effects on postorthodontic white spot lesions. J Evid-Based Dent Pract 18(4):339-342

7. Fernandez-Ferrer L, Vicente-Ruiz M, Garcia-Sanz V, Montiel-Company JM, Paredes-Gallardo V, Almerich-Silla JM, Bellot-Arcis C (2018) Enamel remineralization therapies for treating postorthodontic white-spot lesions: a systematic review. J Am Dent Assoc 149(9):778-786 e2

8. Benson PE, Parkin N, Dyer F, Millett DT, Furness S, Germain P (2013) Fluorides for the prevention of early tooth decay (demineralised white lesions) during fixed brace treatment. Cochrane Database Syst Rev (12):CD003809

9. Hochli D, Hersberger-Zurfluh M, Papageorgiou SN, Eliades T (2017) Interventions for orthodontically induced white spot lesions: a systematic review and meta-analysis. Eur J Orthod 39(2):122-133

10. Taha AA, Patel MP, Hill RG, Fleming PS (2017) The effect of bioactive glasses on enamel remineralization: a systematic review. J Dent 67:9-17

11. Willmot D (2008) White spot lesions after orthodontic treatment. Semin Orthod 14(3):209-219

12. Colfen H (2010) Biomineralization: a crystal-clear view. Nat Mater 9(12):960-961 
13. Thula TT, Rodriguez DE, Lee MH, Pendi L, Podschun J, Gower LB (2011) In vitro mineralization of dense collagen substrates: a biomimetic approach toward the development of bone-graft materials. Acta Biomater 7(8):3158-3169

14. Mahamid J, Sharir A, Addadi L, Weiner S (2008) Amorphous calcium phosphate is a major component of the forming fin bones of zebrafish: indications for an amorphous precursor phase. Proc Natl Acad Sci U S A 105(35):12748-12753

15. Olszta MJ, Cheng X, Jee SS et al (2007) Bone structure and formation: a new perspective. Mater Sci Eng R Reports 58(3-5):77-116

16. Nudelman F, Pieterse K, George A, Bomans PH, Friedrich H, Brylka LJ, Hilbers PA, de With G, Sommerdijk NA (2010) The role of collagen in bone apatite formation in the presence of hydroxyapatite nucleation inhibitors. Nat Mater 9(12):1004-1009

17. Nudelman F, Lausch AJ, Sommerdijk NA, Sone ED (2013) In vitro models of collagen biomineralization. J Struct Biol 183(2):258-269

18. Luo XJ, Yang HY, Niu LN, Mao J, Huang C, Pashley DH, Tay FR (2016) Translation of a solution-based biomineralization concept into a carrier-based delivery system via the use of expanded-pore mesoporous silica. Acta Biomater 31:378-387

19. Vianna JS, Marquezan M, Lau TC, Sant'Anna EF (2016) Bonding brackets on white spot lesions pretreated by means of two methods. Dental Press J Orthod 21(2):39-44

20. Zhang J, Lynch RJM, Watson TF, Banerjee A (2018) Remineralisation of enamel white spot lesions pre-treated with chitosan in the presence of salivary pellicle. J Dent 72:21-28

21. Bakry AS, Abbassy MA (2018) Increasing the efficiency of CPP-ACP to remineralize enamel white spot lesions. J Dent 76:52-57

22. Yang HY, Niu LN, Sun JL, Huang XQ, Pei DD, Huang C, Tay FR (2017) Biodegradable mesoporous delivery system for biomineralization precursors. Int J Nanomedicine 12:839-854

23. Lei J, Guo J, Fu D, Wang Y, Du X, Zhou L, Huang C (2014) Influence of three remineralization materials on physicochemical structure of demineralized enamel. J Wuhan Univ Technol-Mater Sci Ed 29:410-416

24. Rehman I, Hench LL, Bonfield W, Smith R (1994) Analysis of surface layers on 
bioactive glasses. Biomaterials 15(10):865-870

25. Zhang J, Boyes V, Festy F, Lynch RJM, Watson TF, Banerjee A (2018) In-vitro subsurface remineralisation of artificial enamel white spot lesions pre-treated with chitosan. Dent Mater 34(8):1154-1167

26. Xu B, Chen X, Li R, Wang Y, Li Q (2014) Agreement of try-in pastes and the corresponding luting composites on the final color of ceramic veneers. J Prosthodont 23(4):308-312

27. Farzanegan F, Ameri H, Miri Soleiman I, Khodaverdi E, Rangrazi A (2018) An in vitro study on the effect of amorphous calcium phosphate and fluoride solutions on color improvement of white spot lesions. Dent J (Basel) 6(3)

28. Billmeyer FJ, Berns RS, Saltzman M (2000) Billmeyer and Saltzman's principles of color technology, ed 3 edn. Wiley, New York, pp 31-105

29. Lv X, Yang Y, Han S, Li D, Tu H, Li W, Zhou X, Zhang L (2015) Potential of an amelogenin based peptide in promoting reminerlization of initial enamel caries. Arch Oral Biol 60(10):1482-1487

30. Miller MJ, Bernstein S, Colaiacovo SL, Nicolay O, Cisneros GJ (2016) Demineralized white spot lesions: an unmet challenge for orthodontists. Semin Orthod 22(3):193-204

31. Cochrane NJ, Cai F, Huq NL, Burrow MF, Reynolds EC (2010) New approaches to enhanced remineralization of tooth enamel. J Dent Res 89(11):1187-1197

32. Zhou C, Zhang D, Bai Y, Li S (2014) Casein phosphopeptide-amorphous calcium phosphate remineralization of primary teeth early enamel lesions. J Dent 42(1):21-29

33. Li J, Xie X, Wang Y, Yin W, Antoun JS, Farella M, Mei L (2014) Longterm remineralizing effect of casein phosphopeptide-amorphous calcium phosphate (CPP-ACP) on early caries lesions in vivo: a systematic review. J Dent 42(7):769777

34. Cross KJ, Huq NL, Palamara JE, Perich JW, Reynolds EC (2005) Physicochemical characterization of casein phosphopeptide-amorphous calcium phosphate nanocomplexes. J Biol Chem 280(15):15362-15369

35. Philip N (2018) State of the art enamel remineralization systems: the next frontier in caries management. Caries Res 53(3):284-295 
36. Wang Z, Ouyang Y, Wu Z, Zhang L, Shao C, Fan J, Zhang L, Shi Y, Zhou Z, Pan $H$, Tang R, Fu B (2018) A novel fluorescent adhesive-assisted biomimetic mineralization. Nanoscale 10(40):18980-18987

37. Tang F, Li L, Chen D (2012) Mesoporous silica nanoparticles: synthesis, biocompatibility and drug delivery. Adv Mater 24(12):1504-1534

38. Anglin EJ, Cheng L, Freeman WR, Sailor MJ (2008) Porous silicon in drug delivery devices and materials. Adv Drug Deliv Rev 60(11):1266-1277

39. Milly H, Festy F, Andiappan M, Watson TF, Thompson I, Banerjee A (2015) Surface pre-conditioning with bioactive glass air-abrasion can enhance enamel white spot lesion remineralization. Dent Mater 31(5):522-533

40. Featherstone JD, ten Cate JM, Shariati M, Arends J (1983) Comparison of artificial caries-like lesions by quantitative microradiography and microhardness profiles. Caries Res 17(5):385-391

41. Kielbassa AM, Wrbas KT, Schulte-Monting J, Hellwig E (1999) Correlation of transversal microradiography and microhardness on in situinduced demineralization in irradiated and nonirradiated human dental enamel. Arch Oral Biol 44(3):243-251

42. Tramini P, Pelissier B, Valcarcel J, Bonnet B, Maury L (2000) A Raman spectroscopic investigation of dentin and enamel structures modified by lactic acid. Caries Res 34(3):233-240

43. Mohanty B, Dadlani D, Mahoney D, Mann AB (2013) Characterizing and identifying incipient carious lesions in dental enamel using micro-Raman spectroscopy. Caries Res 47(1):27-33

44. Santini A, Pulham CR, Rajab A, Ibbetson R (2008) The effect of a 10\% carbamide peroxide bleaching agent on the phosphate concentration of tooth enamel assessed by Raman spectroscopy. Dental traumatology : official publication of International Association for Dental Traumatology 24(2):220- 223

45. Mohamed AM, Wong KH, Lee WJ, Marizan Nor M, Mohd Hussaini H, Rosli TI (2018) In vitro study of white spot lesion: maxilla and mandibular teeth. Saudi Dent J 30(2):142-150

46. Lu X, Leng Y (2005) Theoretical analysis of calcium phosphate precipitation in simulated body fluid. Biomaterials 26(10):1097-1108

47. Yin Y, Yun S, Fang J, Chen $\mathrm{H}$ (2009) Chemical regeneration of human tooth 
enamel under near-physiological conditions. Chem Commun (Camb)

(39):5892-5894

48. Guo X, Yu L, Chen L, Zhang H, Peng L, Guo X, Ding W (2014) Organoamineassisted biomimetic synthesis of faceted hexagonal hydroxyapatite nanotubes with prominent stimulation activity for osteoblast proliferation. J Mater Chem B 2(13):1760-1763

49. Cooper CL, Cosgrove T, van Duijneveldt JS, Murray M, Prescott SW (2013) Competition between polymers for adsorption on silica: a solvent relaxation NMR and small-angle neutron scattering study. Langmuir : the ACS journal of surfaces and colloids 29(41):12670-12678

50. Olszta MJ, Douglas EP, Gower LB (2003) Scanning electron microscopic analysis of the mineralization of type I collagen via a polymer-induced liquidprecursor (PILP) process. Calcif Tissue Int 72(5):583-591

51. Ma Y, Zhang N, Weir MD, Bai Y, Xu HHK (2017) Novel multifunctional dental cement to prevent enamel demineralization near orthodontic brackets. J Dent 64:58-67

52. Zhang N, Zhang K, Xie X, Dai Z, Zhao Z, Imazato S, Al-Dulaijan YA, Al-Qarni FD, Weir MD, Reynolds MA, Bai Y, Wang L, Xu HHK (2018) Nanostructured polymeric materials with protein-repellent and anti-caries properties for dental applications. Nanomaterials (Basel) 8(6):393 


\section{Figures}
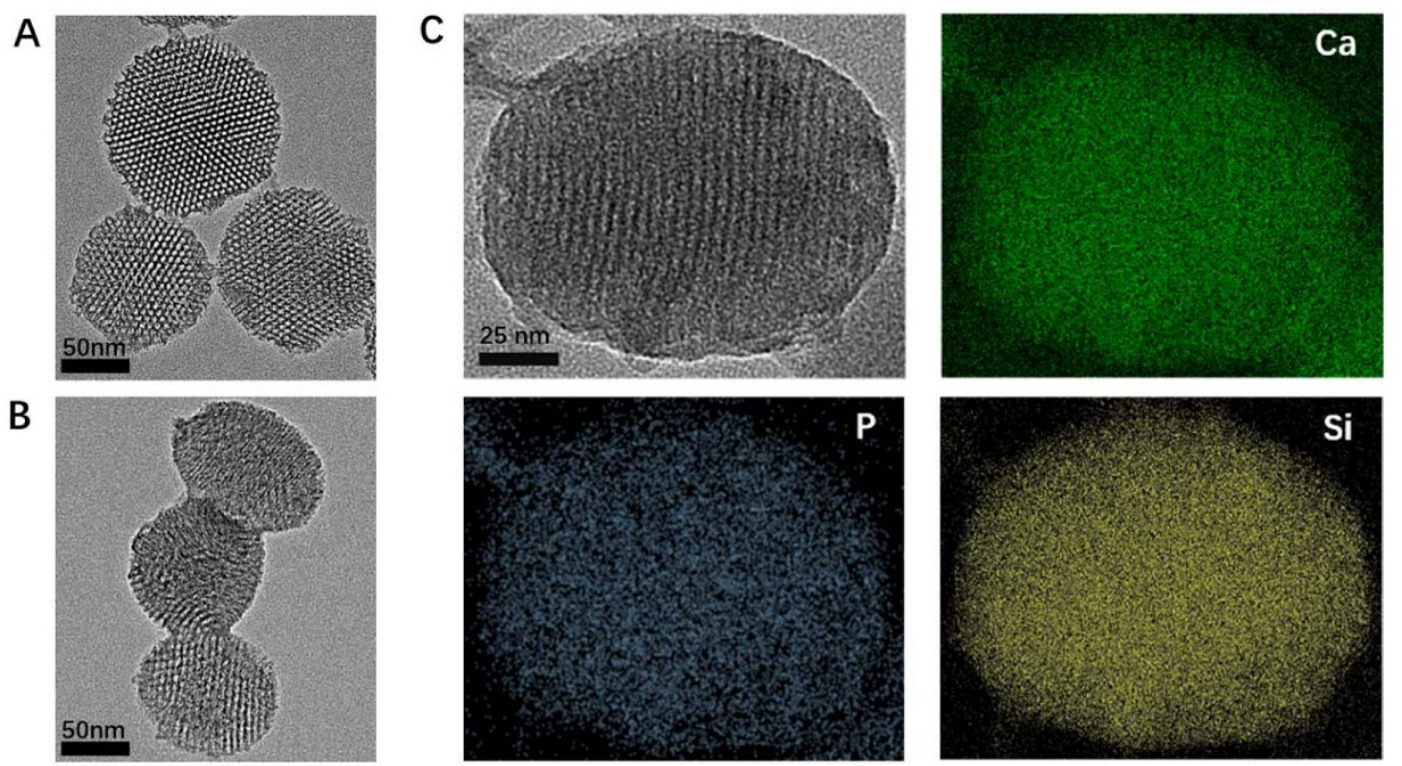

Fig. 1. TEM and STEM-EDX elemental mapping images. TEM image of aMSN showing regular hexagon mesoporosities evenly distributed over the entire aMSN microparticulate (a) and mesoporosities became indistinct and irregular after loading PAA-ACP into aMSN (b). TEM images of one single PAA-ACP@aMSN and its STEM-EDX elemental mapping (c), showing strong intraparticulate $\mathrm{Ca}$ (green) and $\mathrm{P}$ (blue) signals that indicate the infiltration of PAAACP nanoparticles into the mesopores.

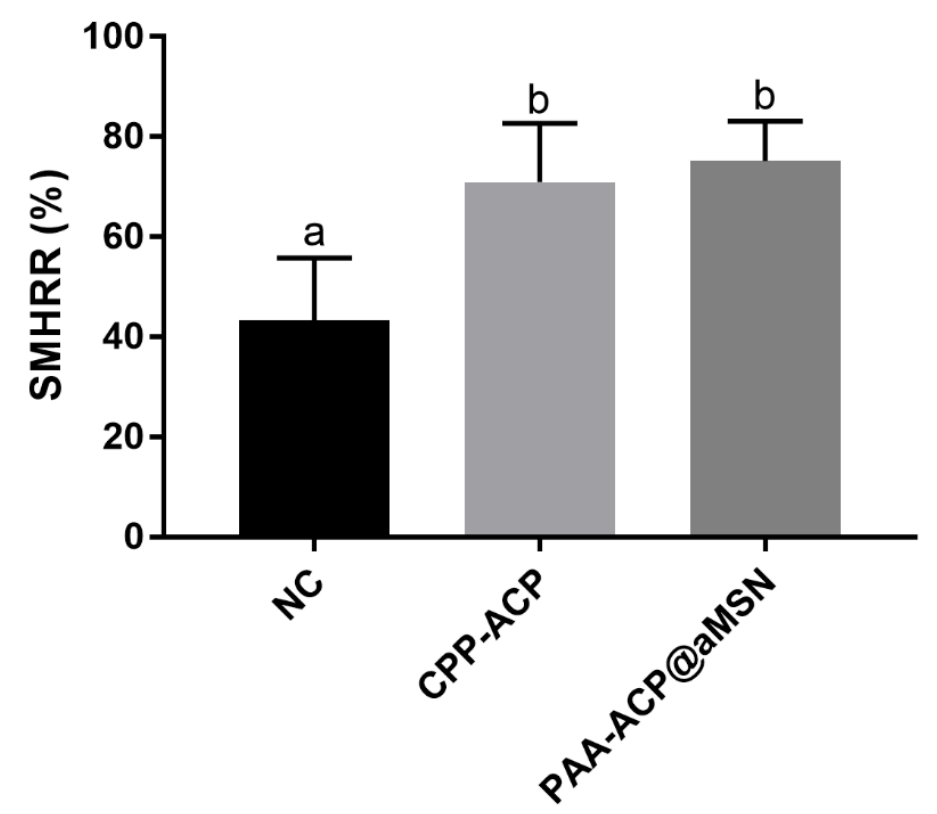

Fig. 2. The surface microhardness recovery ratio (\%SMHRR) of the three groups. Both the CPP- 
ACP and PAA-ACP@aMSN groups exhibited significantly higher \%SMHRR values compared with the NC group, while there was no statistically significant difference between CPP-ACP and PAA-ACP@aMSN groups. Bars with the same letter are not significantly different ( $>$ 0.05).

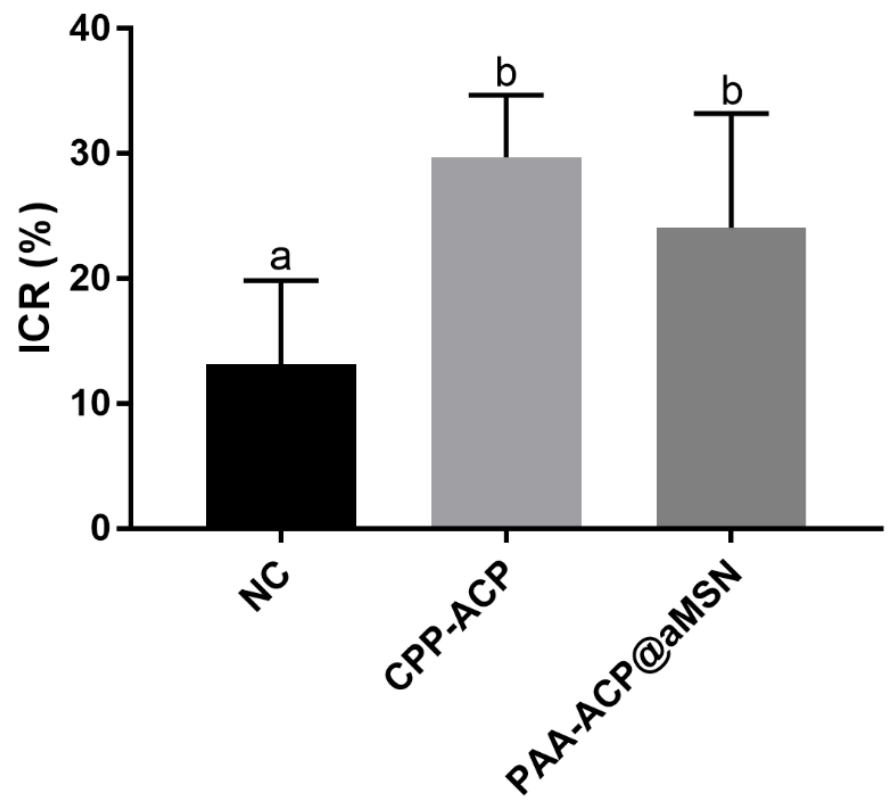

Fig. 3. The intensity change ratio (\%ICR) of the three groups. The \%ICR of CPP-ACP and PAAACP@aMSN were both significantly higher than NC. Bars with the same letter are not significantly different $(P>0.05)$. 


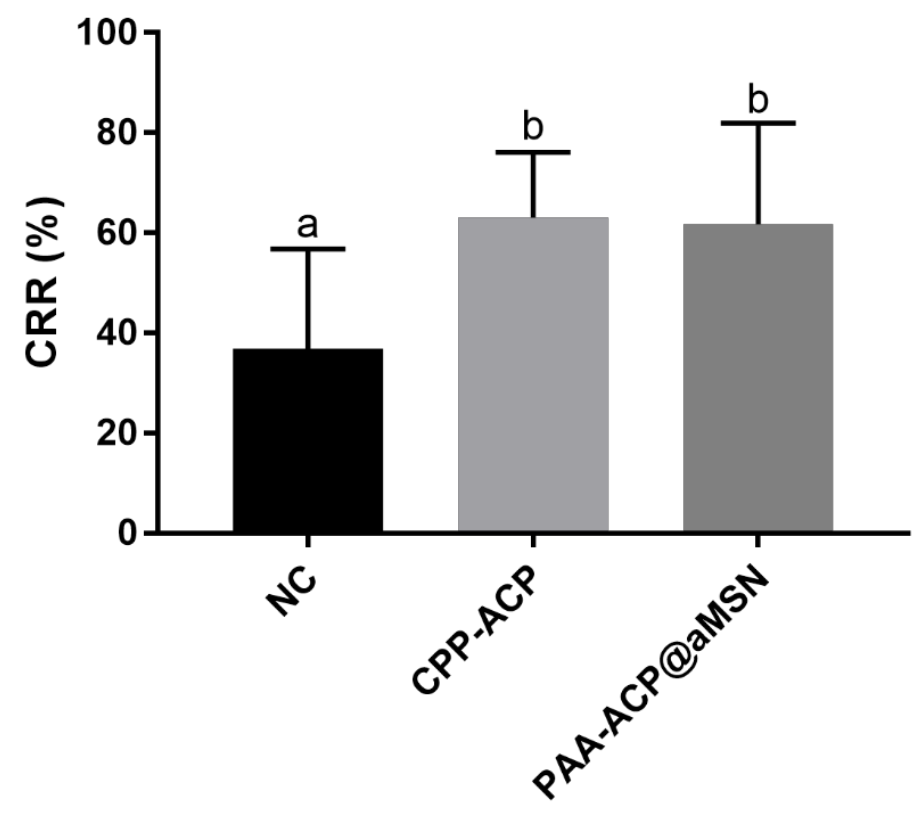

Fig. 4. The color recovery ratio (\%CRR) of the three groups. Both the CPP-ACP and PAAACP@aMSN groups showed significantly greater color recovery ratio compared with the NC group; no significant difference was observed between the CPP-ACP and PAA-ACP@aMSN groups. Bars with the same letter are not significantly different $(P>0.05)$. 


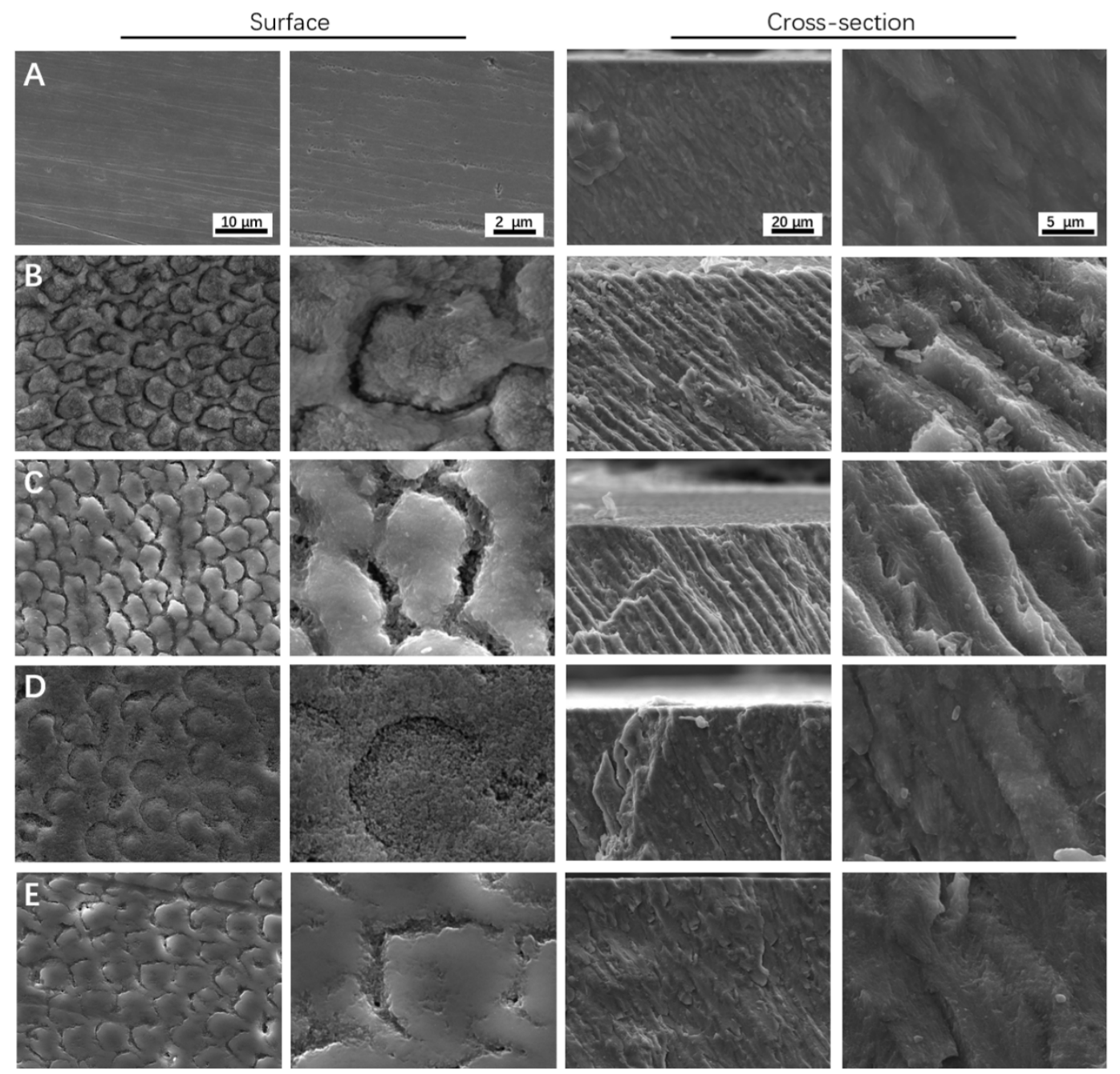

Fig. 5. SEM images for enamel surface and cross-section taken at baseline, after artificial demineralization and after remineralization in the three treatment groups. Images before artificial demineralization (a) showing healthy enamel; images after artificial demineralization (b) showing prism boundaries and inter-prism gaps; images for the NC group (c) showing enamel boundaries and inter-prism gaps indicating no significant remineralization of enamel; images for the CPP-ACP (d) and PAA-ACP@aMSN (e) groups showing prisms and interprism gaps were covered with mineral depositions. 

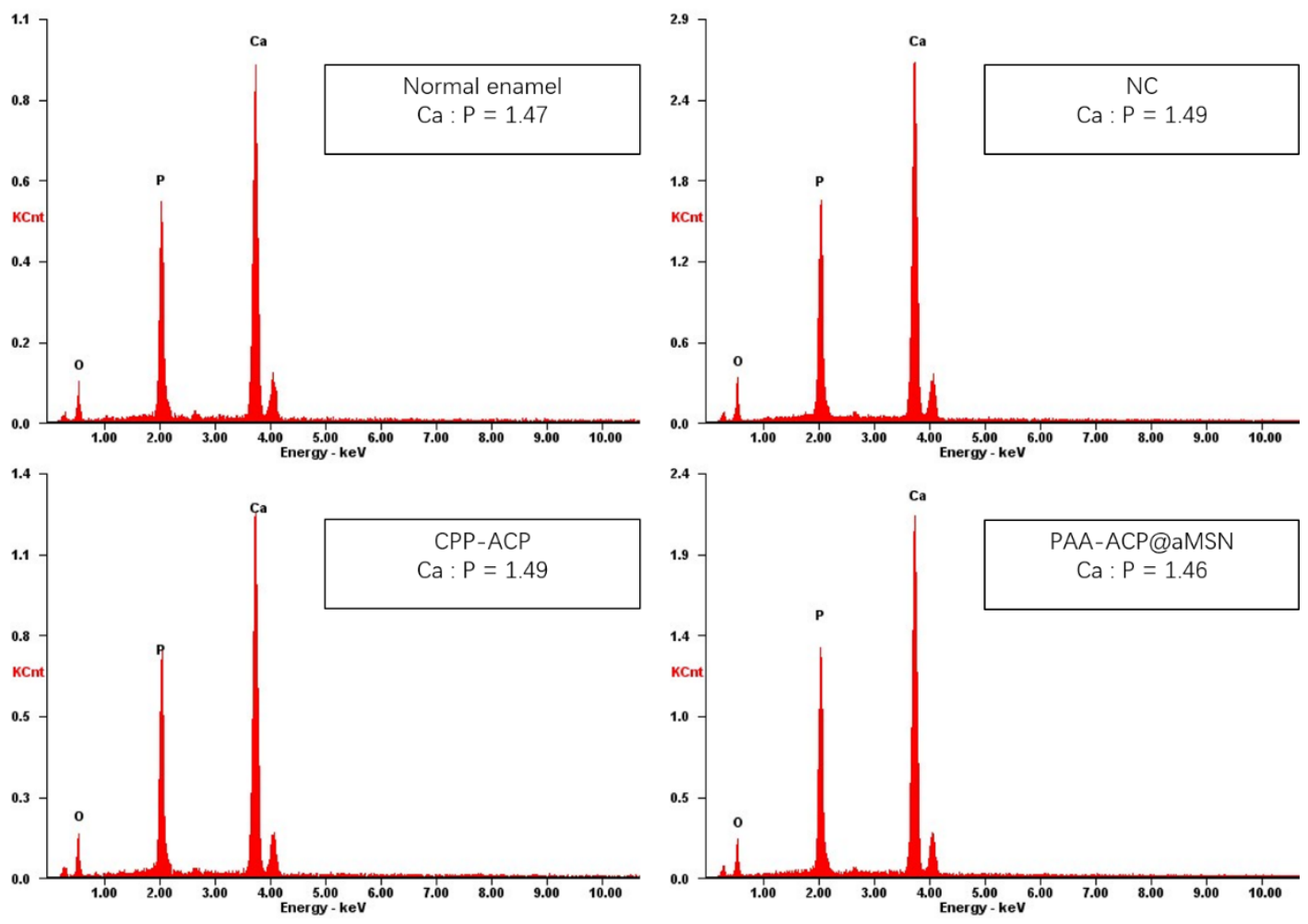

Fig. 6. EDS images for normal enamel and NC, CPP-ACP, and PAA-ACP@aMSN groups. Ratio in textbox showed the calcium-phosphorus atomic ratio. All four samples showed the similar Ca-P atomic ratio. 


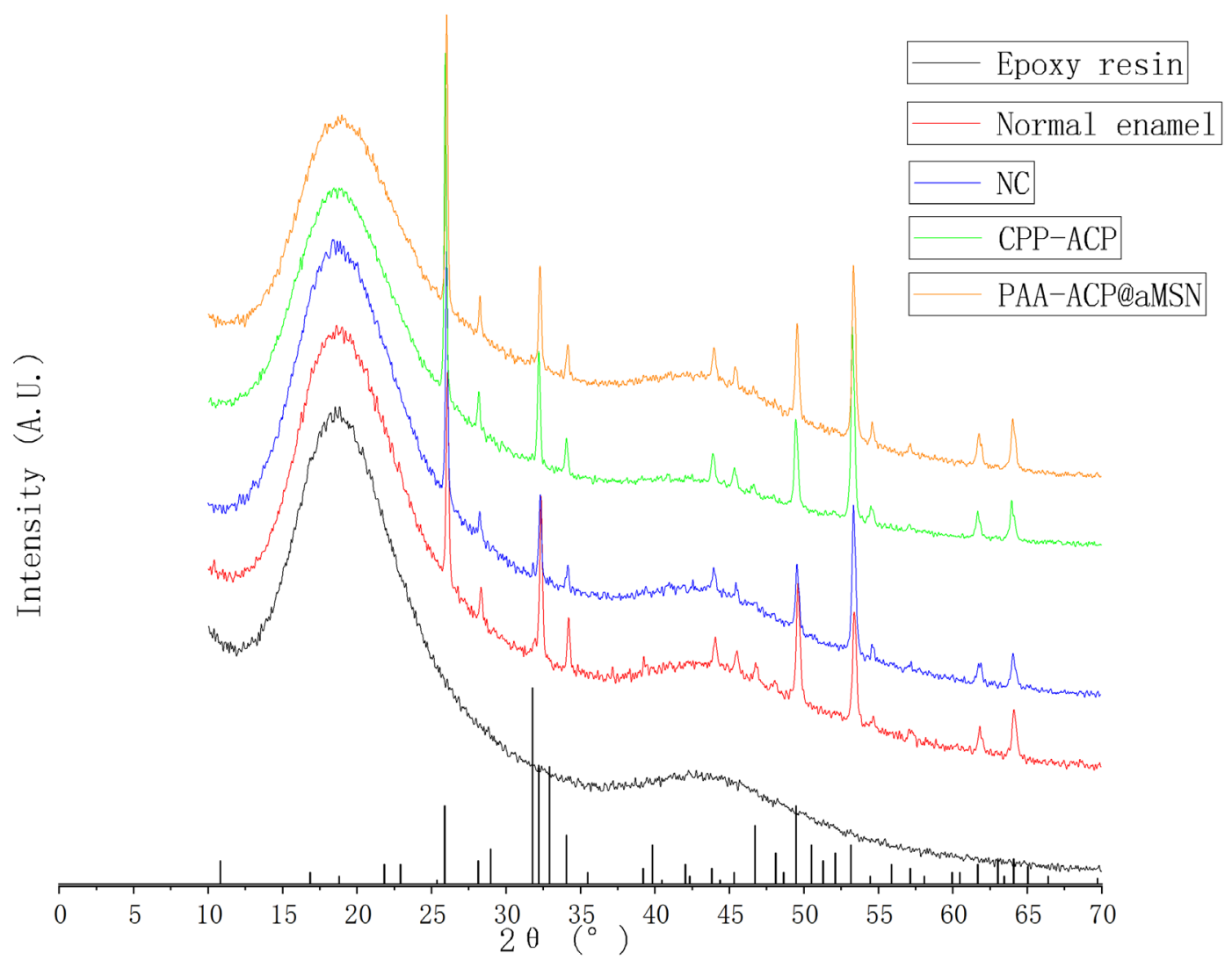

Fig. 7. XRD analysis for normal enamel (red) and NC (blue), CPP-ACP (green), and PAAACP@aMSN (orange) groups after remineralization. At the bottom was a standard XRD pattern (JCPDS 09-0432) of hydroxyapatite. 

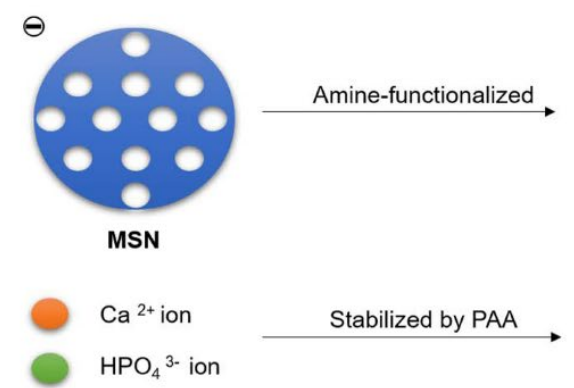

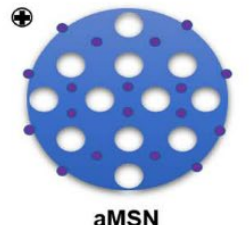

$\ominus$
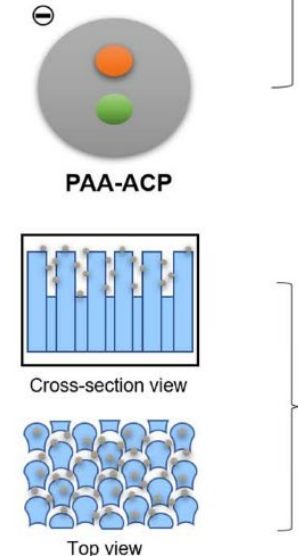

Demineralized ename self-assembly

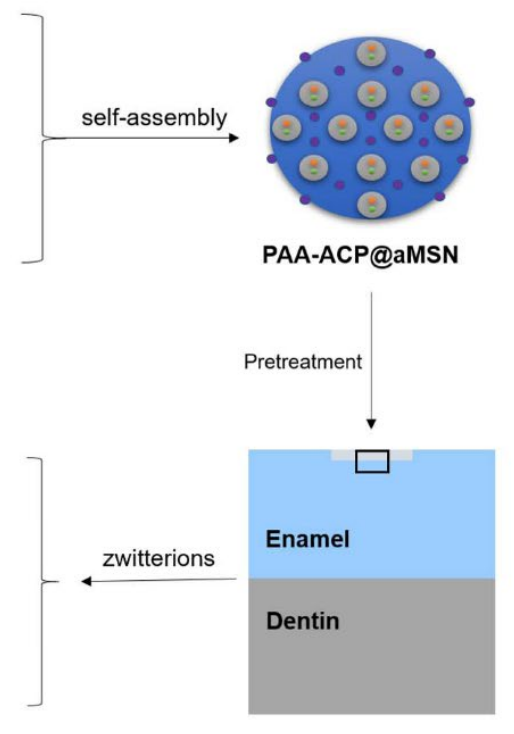

PAA-ACP@aMSN

WSLs model

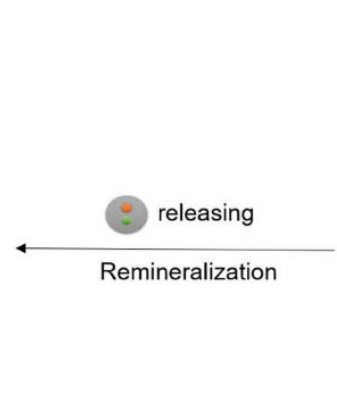

Fig. 8. Schematic diagram for the synthetic process of PAA-ACP@aMSN and its potential remineralization mechanism. aMSN, amine-functionalized mesoporous silica; PAA-ACP, polyacrylic acid-stabilized amorphous calcium phosphate, PAAACP@ aMSN, PAA-ACP loaded aMSN. 


\section{Supplementary material}

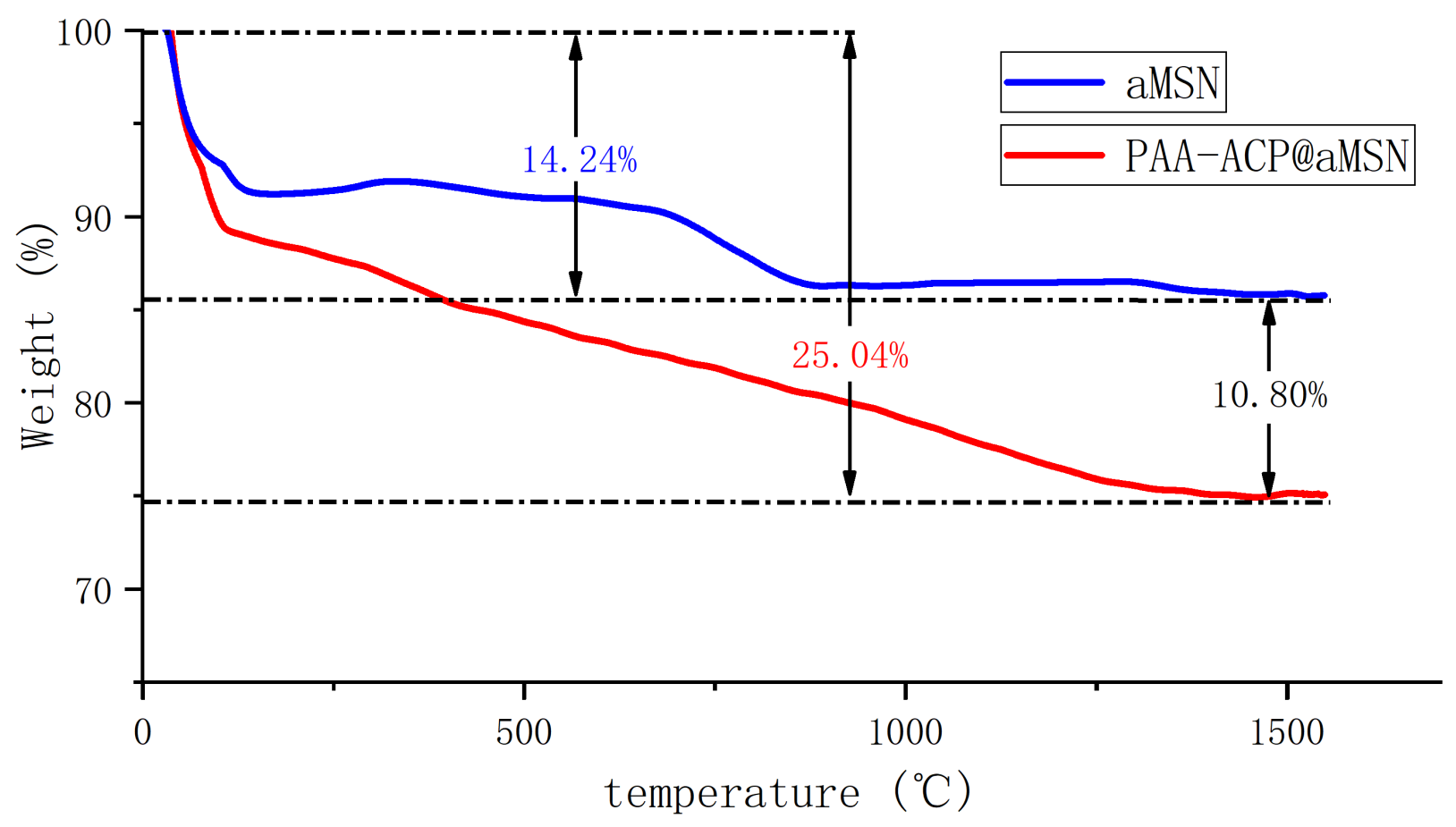

Supplementary Figure 1. Thermogravimetric analysis of aMSN and PAA-ACP@aMSN. aMSN showed a total weight loss of $14.24 \mathrm{wt} \%$ and PAA-ACP@aMSN showed a total weight loss of $25.04 \mathrm{wt} \%$.

Supplementary Table 1. Manufacturer and composition of the CPP-ACP paste used in this study.

\begin{tabular}{|c|c|c|c|}
\hline Product & Manufacturer & Main composition & $\begin{array}{c}\text { CPP- } \\
\text { ACP } \\
\text { content }\end{array}$ \\
\hline $\begin{array}{l}\text { Tooth } \\
\text { Mousse }\end{array}$ & $\begin{array}{c}\text { GC Corp, } \\
\text { Tokyo, Japan }\end{array}$ & $\begin{array}{l}\text { pure water, Glycerol, CPP-ACP, zinc oxide, } \\
\text { CMC-Na, xylitol, D-sorbitol, silicon dioxide, } \\
\text { phosphoric acid, titanium dioxide, guar gum, } \\
\text { sodium saccharin, ethyl-p-hydroxybenzoate, } \\
\text { magnesium oxide, propylene glycol, butyl-p- } \\
\text { hydroxybenzoate, propyl-p-hydroxybenzoate }\end{array}$ & $5 \%-10 \%$ \\
\hline
\end{tabular}


Supplementary Table 2. Absolute values of SMH (Mean \pm SD, VHN) at three time points of three groups and $\mathrm{SMH}$ recovery ratio (Mean $\pm \mathrm{SD}, \%)$ for the three groups.

\begin{tabular}{ccccc}
\hline Group & Baseline & $\begin{array}{c}\text { Before } \\
\text { Remineralization }\end{array}$ & $\begin{array}{c}\text { After } \\
\text { Remineralization }\end{array}$ & $\begin{array}{c}\text { SMH } \\
\text { recovery ratio } \\
(\%)\end{array}$ \\
\hline NC & $378.02 \pm 20.99$ & $236.27 \pm 17.79$ & $297.31 \pm 18.79$ & $43.4 \pm 12.4$ \\
\hline CPP-ACP & $381.23 \pm 20.88$ & $228.24 \pm 25.24$ & $337.29 \pm 16.68$ & $71.0 \pm 11.7$ \\
\hline $\begin{array}{c}\text { PAA- } \\
\text { ACP@aMSN }\end{array}$ & $379.21 \pm 19.85$ & $234.25 \pm 17.95$ & $343.03 \pm 14.71$ & $75.2 \pm 7.9$ \\
\hline
\end{tabular}

Supplementary Table 3. Absolute values of surface Raman intensity (Mean \pm SD) at three time points of three groups and Intensity change ratio (Mean \pm SD, \%) for the three groups.

\begin{tabular}{ccccc}
\hline Group & Baseline & $\begin{array}{c}\text { Before } \\
\text { Remineralization }\end{array}$ & $\begin{array}{c}\text { After } \\
\text { Remineralization }\end{array}$ & $\begin{array}{c}\text { Intensity } \\
\text { change ratio } \\
(\%)\end{array}$ \\
\hline NC & 20540.95 & 14399.95 & 17088.04 & $13.2 \pm 6.7$ \\
& \pm 2249.05 & \pm 1345.18 & \pm 1252.14 & \\
\hline CPP-ACP & 24116.63 & 16182.73 & 23323.49 & $29.7 \pm 4.9$ \\
& \pm 4441.56 & \pm 2365.29 & \pm 3081.83 & \\
PAA- & 22435.26 & 15924.40 & 21416.24 & $24.1 \pm 9.1$ \\
\hline
\end{tabular}

Supplementary Table 4. Absolute values of color change (Mean $\pm \mathrm{SD}$ ) before $(\triangle \mathrm{E} 0$ ) and after $(\triangle \mathrm{E} 1)$ remineralization of three groups and color recovery ratio (Mean $\pm \mathrm{SD}, \%)$ for the three groups.

\begin{tabular}{cccc}
\hline Group & $\Delta \mathrm{E} 0$ & $\Delta \mathrm{E} 1$ & $\begin{array}{c}\text { Color } \\
\text { recovery ratio } \\
(\%)\end{array}$ \\
\hline NC & $3.35 \pm 1.16$ & $1.24 \pm 0.78$ & $36.9 \pm 20.0$ \\
\hline CPP-ACP & $2.98 \pm 0.93$ & $1.84 \pm 0.60$ & $63.0 \pm 13.1$ \\
\hline $\begin{array}{c}\text { PAA- } \\
\text { ACP@aMSN }\end{array}$ & $3.65 \pm 1.51$ & $2.27 \pm 1.14$ & $61.7 \pm 20.2$ \\
\hline
\end{tabular}

